Capítulo 13

\title{
DISTRIBUCIÓN DEL PODER TRIBUTARIO EN ARGENTINA EL RÉGIMEN DE COPARTICIPACIÓN FEDERAL DE IMPUESTOS
}

\author{
Gastón Francisco Vidal Quera ${ }^{1}$ \\ Katia Palencia Sánchez ${ }^{2}$
}

\section{Resumen}

El poder tributario puede ser definido como la posibilidad o potestad de establecer prestaciones patrimoniales coactivas - tributos - a aquellos sujetos que se encuentran en el ámbito de la soberanía del respectivo Estado. Los Estados son los que detentan el poder coactivo, dado por la posibilidad de detraer del patrimonio de los contribuyentes dinero con fines para que ingresen al erario público. La República Argentina es un país federal, el cual se encuentra dividido en tres niveles de gobierno, el Estado Nacional, las provincias y la Ciudad Autónoma de Buenos Aires y las municipalidades o comunas, según lo define cada una de las provincias a las que pertenecen. Cada uno de esos tres niveles de gobierno cuenta con el respectivo poder tributario y su uso concurrente o conjunto genera en los casos concretos el fenómeno de la denominada "doble o múltiple imposición". Ese fenómeno consiste, en líneas generales en que dos entes con

1 Especialista en Derecho Tributario. Abogado. Docente Investigador de la Universidad de Palermo. Email: gvidalquera@yahoo.com.ar

2 Doctorante en Ciencias Políticas y de la Administración y Relaciones Internacionales, Magíster en gobierno y Administración Pública, Especialista en Derecho Público. Abogada. Adscrita al Centro de investigación Sociojurídicas de la Corporación Universitaria del Caribe GISCER. Email: Katia.palencia@cecar.edu.co 
poder tributario graven a un mismo sujeto, actividad u operación en un mismo momento temporal, siempre y cuando cuenten con la atribución constitucional o legal para realizar tal cobro. Veremos que el fenómeno de la doble o múltiple imposición es perfectamente válido desde el punto de vista de nuestra Constitución Nacional y para evitar el mismo, nuestro país, conforme se desarrollará en otro punto, estableció mecanismos de coordinación a nivel horizontal y vertical, siendo los más importantes el régimen de coparticipación federal de impuestos, ley 23.548 y el Convenio Multilateral que es aplicable únicamente al impuesto sobre los ingresos brutos.

Palabras clave: distribución, poder tributario, régimen, coparticipación federal e impuestos.

\section{Abstract}

The taxing power can be defined as the possibility or power to establish coercive patrimonial benefits -taxes- to those subjects that are in the scope of the sovereignty of the respective State. The States are the ones that hold the coercive power, given by the possibility of taking money from the patrimony of the taxpayers for purposes of entering the public treasury. The Republic of Argentina is a federal country, which is divided into three levels of government, the National State, the provinces and the Autonomous City of Buenos Aires and the municipalities or communes, as defined by each of the provinces to which they belong. Each of these three levels of government has the respective taxing power and their concurrent or joint use generates in specific cases the phenomenon of "double or multiple taxation". This phenomenon consists, in general terms, of two entities with taxing power taxing the same subject, activity or operation at the same time, provided that they have the constitutional or legal attribution to make such collection. We will see that the phenomenon of double or multiple taxation is perfectly valid from the point of view of our National Constitution and in order to avoid it, our country, as it will develop in another point, established coordination mechanisms at horizontal and vertical level, the most important being the federal tax sharing regime, Law 23.548 and the Multilateral Agreement that is applicable only to the gross income tax.

Keywords: distribution, tax power, regime, federal co-participation and taxes 


\section{Introducción}

Sobre la doble imposición la Corte Suprema de Justicia de la Nación ha ratificado su constitucionalidad al sostener hace muchísimos años, y en forma previa a la actual redacción de la Constitución, que:

(...) en general, los atributos indirectos al consumo interno, o sean los impuestos aludidos, pueden ser constitucionalmente establecidos por la Nación y por las provincias, en ejercicio de facultades concurrentes y sin óbice alguno determinado por incompatibilidades de orden institucional. El poder impositivo del gobierno central a este respecto, así como la potestad concurrente de los estados para establecer los mismos gravámenes sobre la misma materia imponible se ha derivado de la inteligencia atribuida al artículo 4 de la Constitución Nacional (Corte Suprema de Justicia de la Nación, 1927).

Es decir que desde el estricto punto de vista de la Constitución Nacional, dos entes de gobierno pueden cobrar tributos sobre mismas manifestaciones económicas o de capacidad contributiva (podría haber impuestos indirectos provinciales y nacionales), pero para ello existen los mecanismos de coordinación que se explicarán.

Ahora bien, en primer lugar, cabe analizar la distribución del poder tributario que tiene nuestra Constitución Nacional histórica de 1853/60, en el texto actualmente vigente con la reforma implementada en el año 1994. El Estado Nacional tiene poder tributario exclusivo y excluyente sobre determinadas materias y concurrente con las Provincias en otras, y ciertos casos en que la tributación es excepcional. En efecto, el artículo 75 inciso 1) determina que el Estado Nacional tiene competencia exclusiva y excluyente en la regulación de todo lo atinente a la materia aduanera, con lo cual es el único ente que puede regular los tributos sobre el comercio exterior e internacional. Ni las Provincias ni sus municipios pueden regular tributos sobre esas materias, con lo cual no pueden gravarse las exportaciones, aspecto éste que se analizará en otro capítulo de esta obra. 


\section{La distribución del poder tributario en la Constitución Nacional}

La Constitución Nacional continúa considerando una distribución del poder tributario basada en la distinción entre tributos "directos e indirectos". Desde el punto de vista de la doctrina, es una distinción que presenta controversias y no del todo clara. El artículo 75 de la Constitución en su inciso 2, dispone que corresponde al Congreso:

Imponer contribuciones indirectas como facultad concurrente con las provincias. Imponer contribuciones directas, por tiempo determinado, proporcionalmente iguales en todo el territorio de la Nación, siempre que la defensa, seguridad común y bien general del Estado lo exijan. Las contribuciones previstas en este inciso, con excepción de la parte o el total de las que tengan asignación específica, son coparticipables.

Se trata de una distinción que es confusa y que genera bastante controversia, pero que ha sido mantenida por el convencional constituyente del año 1994. Se puede decir desde punto de vista de la distinción entre directo e indirecto, lo importante es la denominada traslación económica, siendo trasladables los indirectos y los directos no. Sin embargo, no es algo tan claro y lineal. Con claridad se ha dicho:

(...) en virtud de que la traslación depende de gran cantidad de factores, no tiene carácter científico efectuar sobre esa base la distinción. En nuestro país, sólo en el IVA la ley prevé la traslación al consumidor final. Observemos que un impuesto considerado tradicionalmente como directo ha sido el impuesto a la renta, lo cual no obstó a que, al ser gravadas las sociedades, fuera factible de traslación, esto es, de transferir la carga tributaria a sujetos que no revisten el carácter de sujetos pasivos (García, 2017, p. 65) .

Pero el tema de la traslación o no del tributo no es una distinción válida para este tema, sin embargo, es el que nuestra Constitución Nacional sigue adoptando como criterio de distribución del poder tributario. En tal sentido, puede decirse que son directos los relativos al patrimonio o renta, como el impuesto sobre los bienes personales y el impuesto a las ganancias, y la doctrina engloba como indirectos a los impuestos a los consumos, como 
al valor agregado o consumos específicos como impuestos internos. En tal sentido, podría perfectamente establecerse un impuesto al valor agregado provincial en conjunto con uno nacional. Y por su parte las provincias podrían disponer y legislar de un impuesto sobre la renta, siendo ello perfectamente constitucional.

En lo que respecta a los municipios y el poder tributario, la Constitución Nacional dispone, de acuerdo al artículo 5, que cada Provincia deberá dictar su Constitución, y que el Gobierno Federal le garantiza el ejercicio de sus instituciones en la medida que garanticen, entre otras cosas, el régimen municipal. Respecto al alcance del mismo, se dispuso una forma de consenso en la reforma constitucional del año 1994, en donde se plasmó que "Cada provincia dicta su propia constitución, conforme a lo dispuesto por el Artículo $5^{\circ}$ asegurando la autonomía municipal y reglando su alcance y contenido en el orden institucional, político, administrativo, económico y financiero". La Corte Suprema recientemente ha sostenido respecto a la autonomía municipal que:

(...) este Tribunal recordó algunos de los aspectos sustanciales que regulan la efectiva vigencia del régimen de autonomía de los municipios sosteniendo, al precisar el alcance del art. $5^{\circ}$ de la Constitución Nacional, que la necesaria existencia de un régimen municipal impuesto por dicha norma "determina que las leyes provinciales no sólo deben imperativamente establecer los municipios, sino que no pueden privarlos de las atribuciones mínimas necesarias para desempeñar su cometido. Si los municipios se encontrasen sujetos en esos aspectos a las decisiones de una autoridad extraña -aunque se tratare de la provincial - ésta podría llegar a impedirles desarrollar su acción específica, mediante diversas restricciones o imposiciones, capaces de desarticular las bases de su organización funcional (...) la reforma de 1994 al introducir el concepto de autonomía municipal en el art. 123 remarco la trascendencia del órgano municipal en el diseño federal argentino y su caracterización como el orden de gobierno de mayor proximidad con la ciudadanía (Corte Suprema de Justicia de la Nación, sentencia del 23 de agosto del 2018). 
La conclusión personal es que serán tan autónomas en materia tributaria como la provincia a la que pertenecen les permita, siempre sin desconocer que deben contar con los recursos financieros, propios y los que reciban de la Provincia, que les permita cumplir adecuadamente con su cometido, de acuerdo al alcance de autonomía previsto por la Corte Suprema. Así por caso, las provincias más "centralistas" no son tan autónomos sus municipios, como la de Buenos Aires y Santa Fe. La Constitución de la Provincia de Santa Fe dispone en el artículo 107 que:

Los municipios son organizados por la ley sobre la base: (...) 3) con las atribuciones necesarias para una eficaz gestión de los intereses locales, a cuyo efecto la ley los proveerá de recursos financieros suficientes. A este último fin, pueden crear, recaudar y disponer libremente de recursos propios provenientes de las tasas y demás contribuciones que establezca en su jurisdicción. Tienen, asimismo, participación en gravámenes directos e indirectos que recaude la Provincia con un mínimo del cincuenta por ciento del producido del impuesto inmobiliario, de acuerdo con un régimen especial que asegure entre todos ellos una distribución proporcional, simultánea e inmediata.

Pero más al sur de nuestro país sí son más autónomos en materia tributaria, como el caso de Santa Cruz que en su Constitución Provincial en el artículo 141 dispone:

Esta Constitución reconoce autonomía política, administrativa, económica y financiera a todos los Municipios. Aquellos que dicten su Carta Orgánica Municipal, gozarán además de autonomía institucional. La autonomía municipal que aquí se reconoce no podrá ser limitada por ley ni autoridad alguna.

En el caso de la Provincia de Chubut se dispone en la constitución provincial en su artículo 239: "Los municipios tienen rentas y bienes propios, siendo exclusiva su facultad de imposición respecto de las personas, cosas o formas de actividad sujetas a jurisdicción municipal". En resumen, la distribución del poder tributario en la Constitución Nacional es la siguiente, debiendo ser complementadas con las Constituciones provinciales en lo que respecta al régimen municipal en particular: 


\section{a) Estado Nacional:}

1. Tiene competencia exclusiva y excluyente en cuestiones de comercio exterior, Es por ello que es constitucional que cobren derechos de exportación e importación y que los mismos resultaran coparticipables.

2. Tiene facultades concurrentes con las provincias en imposición indirecta,

3. Tiene facultades excepcionales, en materia de imposición directa, por tiempo determinado, proporcionalmente iguales en todo el territorio de la Nación, siempre que la defensa, seguridad común y bien general del Estado lo exijan.

\section{b) Las provincias y la Ciudad Autónoma de Buenos Aires:}

1. No pueden gravar de ninguna manera el comercio exterior con ninguna clase de tributo.

2. Tienen facultades para establecer imposición indirecta y directa en forma amplia.

\section{c) Las municipalidades de las provincias:}

1. Tienen poder tributario, con el alcance y contenido que les conceda la provincia a la que pertenecen.

Como veremos seguidamente no es el sistema vigente en nuestro país, ya que la distribución de potestades tributarias está basada en un régimen de coordinación en el cual el Estado Nacional recauda y reparte, y las provincias se abstienen de gravar sobre manifestaciones de capacidad contributiva que podrían perfectamente hacerlo (renta, patrimonio y consumo), con ciertas excepciones relacionadas con los tributos que históricamente recaudaban. En algún punto, el régimen vigente debilita el federalismo en materia tributaria, ya que muchas veces las provincias carecen de los recursos que necesitan, por la manera en que está instrumentado el régimen y la manera en que el mismo se desenvuelve. Puntualmente está vigente, el régimen de coparticipación federal de impuestos, que es la ley 23.548 en vigor desde el año 1998, sin que haya sido reemplazado pese a que el convencional constituyente así lo ha exigido en la reforma de 1994. 
Distribución del poder tributario en Argentina el régimen de Coparticipación Federal de impuestos

Se trata del mecanismo de coordinación más importante, por la cantidad de impuestos que engloba, pero no es el único vigente.

\section{El régimen de coordinación actualmente vigente: la ley de coparticipación federal de impuestos}

En forma preliminar, cabe tener en cuenta que el régimen de coparticipación forma parte del federalismo de concertación para nuestro más Alto Tribunal. Así, expresó que el mismo tiende a "establecer mediante la participación concurrente del Estado Nacional y las provincias un programa, destinado a adoptar una política uniforme que armonice y posibilite la finalidad común de crecimiento de la economía nacional y de reactivación de las economías regionales" (Corte Suprema de Justicia de la Nación, s.f. Fallos 322:1781). Agregando que:

(...) ese tipo de acuerdos constituyen manifestaciones positivas del llamado federalismo de concertación, inspirado en la búsqueda de un régimen concurrente en el cual las potestades provinciales y nacionales se unan en el objetivo superior de lograr una política uniforme en beneficio de los intereses del Estado Nacional y de las provincias (Corte Suprema de Justicia de la Nación, s.f. Fallos: 324: 4226).

Sin embargo, y en forma paradójica la ley en sí, no tiene naturaleza federal y su vulneración no permite acceder a instancia originaria de la Corte Suprema ni ante los juzgados federales con asiento en las provincias, como se desarrollará seguidamente, por ser una norma especial del "derecho público provincial". La ley 23.548 22, con sus modificatorias, es el régimen actualmente vigente para distribuir las facultades impositivas de Argentina que no ha sido reemplazado hasta el presente. Ello por cuanto su vigencia inicial era hasta el 31 de diciembre de 1989, pero la misma se prorroga automáticamente ante la inexistencia de un régimen sustitutivo, el art. 15 de la ley 23.548.

A continuación, se resumirán los aspectos esenciales del régimen haciendo especial referencia en lo que respecta particularmente a la tributación local en el capítulo pertinente. Por un lado, se dispone que la masa de fondos a distribuir se forma con la recaudación de todos los impuestos nacionales que existen o lo que se creen en el futuro con las siguientes excepciones: 
a) Derechos de importación y exportación previstos en el artículo 4 de la Constitución Nacional

b) Aquellos cuya distribución, entre la Nación y las provincias, esté prevista o se prevea en otros sistemas o regímenes especiales de coparticipación;

c) Los impuestos y contribuciones nacionales con afectación específica a propósitos o destinos determinados, vigentes al momento de la promulgación de esta Ley, con su actual estructura, plazo de vigencia y destino. Cumplido el objeto de creación de estos impuestos afectados, si los gravámenes continuaran en vigencia se incorporarán al sistema de distribución de esta Ley;

d) Los impuestos y contribuciones nacionales cuyo producido se afecte a la realización de inversiones, servicios, obras y al fomento de actividades, que se declaren de interés nacional por acuerdo entre la nación y las provincias. Dicha afectación deberá decidirse por Ley del Congreso Nacional con adhesión de las Legislaturas Provinciales y tendrá duración limitada.

Cumplido el objeto de creación de estos impuestos afectados, si los gravámenes continuaran en vigencia se incorporarán al sistema de distribución de esta Ley. Asimismo, considérense integrantes de la masa distribuible, el producido de los impuestos, existentes o a crearse, que graven la transferencia o el consumo de combustibles, incluso el establecido por la Ley $\mathrm{N}^{\circ}$ 17.597, en la medida en que su recaudación exceda lo acreditado el Fondo de Combustibles creado por dicha ley. Como se puede ver, la "masa coparticipable" si bien parece amplia, tiene varios tributos que la van "recortando" o haciendo más pequeña de lo que realmente es, así las cosas no incluye los tributos sobre el comercio exterior, o aquellos con recaudación específica que desde el punto de vista cualitativo son relevantes.

Sobre la masa efectivamente coparticipable, se dispone una distribución primaria, entre el Estado Nacional y las Provincias, y luego una distribución secundaria entre las Provincias entre sí. Respecto a la distribución primaria, el monto total se distribuye de la siguiente manera: a) El cuarenta y dos con treinta y cuatro centésimos por ciento $(42,34 \%)$ en forma automática a la Nación; b) El cincuenta y cuatro con sesenta y seis por ciento $(54,66 \%)$ 
en forma automática al conjunto de provincias adheridas y c) El dos por ciento (2\%) en forma automática para el recupero del nivel relativo de las siguientes provincias: Buenos Aires 1,5701\%, Chubut 0,1433\%, Neuquén 0,1433\% y Santa Cruz 0,1433\%; d) El uno por ciento (1\%) para el Fondo de Aportes del Tesoro Nacional a las provincias.

Luego existe una distribución secundaria, conforme a los porcentajes que determina la ley: Buenos Aires 19,93\%, Catamarca 2,86\%, Córdoba $9,22 \%$, Corrientes 3,86\%, Chaco 5,18\%, Chubut 1,38\%, Entre Ríos 5,07\%, Formosa 3,78\%, Jujuy 2,95\%, La Pampa 1,95\%, La Rioja 2,15\%, Mendoza 4,33\%, Misiones 3,43\%, Neuquén 1,54\%, Rio Negro 2,62\%, Salta 3,98\%, San Juan 3,51\%, San Luis 2,37\%, Santa Cruz 1,38\%, Santa Fe 9,28\%, Santiago del Estero 4,29\% y Tucumán 4,94\%. Es importante considerar como se forma la masa coparticipable y que en rigor de verdad la misma está recortada por el Estado Nacional para las provincias. En tal sentido, debe considerarse que existen reclamos por parte de las provincias hacia el Estado Nacional relacionados con la manera en la que se distribuye esta masa coparticipable y las detracciones que realiza, en forma unilateral el Estado Nacional. Por citar uno de ellos, el Alto Tribunal ha dicho en sentencia del 24 de noviembre de 2015 en los autos, Santa Fe, Provincia de c/ Estado Nacional s/ acción declarativa de inconstitucionalidad, donde se sostuvo que:

(...) el decreto 1399/2001 constituye una disposición de carácter legislativo dictada por el Presidente de la Nación fuera de las bases de la delegación de facultades contenidas en el artículo $1^{\circ}$, apartado I, incisos a y b de la ley 25.414 y, por consiguiente, violatorio de la prohibición contemplada en el artículo 99, inciso 3, segundo párrafo de la Constitución Nacional. (Corte Suprema de Justicia Nacional, s.f. Fallos 338: 1389)

Y al declarar su inconstitucionalidad dispuso que a la Provincia de Santa Fe no se le detraigan los importes del citado Decreto, por resultar el mismo inconstitucional. Se trata de un caso, que ha sido seguido por muchas otras provincias en donde se ha reclamado la detracción unilateral de masa coparticipable por parte del Estado Nacional. Como se puede ver el tema de la coparticipación y su distribución, y la masa que se aplica la misma, es un tema complejo que ha generado muchos litigios entre las 
provincias y el Estado Federal, desnaturalizando la esencia de este tan importante régimen.

\section{Naturaleza jurídica de la ley de coparticipación federal: ¿una norma que no es federal}

Es importante analizar la naturaleza jurídica de la ley de coparticipación para poder analizar el alcance que se le puede dar cuando la misma es vulnerada. La Corte Suprema de Justicia de la Nación en el conocido precedente "Papel Misionero SA c/ Provincia de Misiones" dispuso ya en el 2009 que:

(...) las leyes-convenio -entre las que cabe incluir el régimen de coparticipación federal y el Convenio Multilateral en sus respectivas ratificaciones locales por medio de sus legislaturas provinciales- hacen parte, aunque con diversa jerarquía, del derecho público provincial y que esa condición asume la ley de coparticipación federal, por lo que su violación no abre la instancia originaria ante esta Corte. (Fallos 332:1007, sf.)

Se comparta o no esta postura, para el Alto Tribunal la ley de coparticipación es una suerte de ley provincial especial, que no puede ser derogada en forma unilateral. Se ha dicho sobre el tema que:

(... ) las demás creaciones legales del federalismo de concertación, configuran el derecho intrafederal y se incorporan una vez ratificados por las legislaturas al derecho público interno de cada Estado Provincial, aunque con la diversa jerarquía que les otorga su condición de ser expresión de la voluntad común de los órganos superiores de nuestra organización constitucional: nación y provincias. Esa gestación institucional los ubica con un rango normativo específico dentro del derecho federal. Prueba de su categoría singular es que no es posible su derogación unilateral por cualquiera de las partes (Fallos: 322:1781, s.f).

Concluyendo que:

(...) esa jerarquía superior que cabe reconocerle a los acuerdos intrafederales y a las leyes convenio es inherente a su propia naturaleza contractual en la que concurren las voluntades de 
los órganos superiores de la Constitución en aras de alcanzar objetivos comunes (...) la esencia misma del derecho intrafederal impone concluir que las leyes-convenio y los pactos que lo componen no se encuentra en una esfera de disponibilidad individual de las partes, y solo pueden ser modificados o renovados por otro acuerdo posterior de la misma naturaleza, debidamente ratificado por leyes emanadas de las jurisdicciones intervinientes (Sentencia del 24 de noviembre del 2015).

En concreto para el Alto Tribunal, la ley de coparticipación por su forma de gestación tiene una naturaleza "contractual", no es posible que sea derogada por ninguna de las partes y forma parte del derecho público provincial con un particular enfoque. Pese que parece que no hay nada más federal que una ley de coparticipación, en este caso, no se considera de esa manera a la ley en cuestión. Las consecuencias prácticas de tal pronunciamiento están dadas por el hecho que cualquier vulneración al régimen al formar parte del derecho público local, hace que nazca la competencia de los tribunales locales, en los cuales como principio general casi sin excepción rige el principio del pago previo o "solve et repete". En otras palabras, no se podrá ir a los tribunales federales o en instancia originaria ante la Corte Suprema de Justicia de la Nación cuando ello proceda, por tratarse de una cuestión local, que abre la competencia de los juzgados locales y no federales. Es una importante limitación que se presenta, ya que como se desarrollará en otro capítulo, los contribuyentes que cuestionan tributos interponen acciones declarativas de certeza, con pedidos de medida cautelar, para intentar no abonar el tributo, pero es una vía que a nivel local puede no ser tan fuerte como a nivel federal cuando se cuestiona la aplicación del régimen de coparticipación.

\section{La Comisión Federal de Impuestos: órgano de control del régimen}

El órgano de control de cumplimiento del régimen de coparticipación es la Comisión Federal de Impuestos, la que de acuerdo al artículo 10 de la ley "(...) estará constituida por un representante de la nación y uno por cada provincia adherida. Estos representantes deberán ser personas especializadas en materia impositiva a juicio de las jurisdicciones designantes (...)". Tiene un Comité Ejecutivo constituido e integrado por el representante de la Nación y los de ocho (8) provincias. 
Este importante órgano, tiene como función la de controlar que a los distintos fiscos le llegue la correspondiente liquidación y que las partes intervinientes cumplan con las obligaciones a su cargo. Pero a lo referente a la tributación local, las facultades más importantes están dadas en el artículo 10 incisos d) en donde se establece que puede:

Decidir de oficio o a pedido del Ministerio de Nación, de las provincias o de las municipalidades, si los gravámenes nacionales o locales se oponen o no y, en su caso, en qué medida a las disposiciones de la presente. En igual sentido, intervendrá a pedido de los contribuyentes o asociaciones reconocidas. Sin perjuicio de las obligaciones de aquellos de cumplir las disposiciones fiscales pertinentes.

Y en el inciso e) Dictar normas generales interpretativas de la presente ley.

Respecto a la facultad de resolver si una norma está en pugna o no con el régimen, es importante remarcar que los contribuyentes pueden solicitar la intervención de la Comisión Federal de Impuestos, sin costo alguno y presentando su caso ante la misma, incluso sin necesidad de patrocinio o asistencia letrada, como consta en el artículo $4^{\circ}$ de la Ordenanza Procesal. Es así, para el caso en que se considere que una norma está en pugna, además de las impugnaciones administrativas en la jurisdicción y ante la justicia local provincial, se puede presentar el caso, solicitando la intervención y resolución por parte de la Comisión. Es importante la decisión de este órgano, por cuanto su declaración en pugna puede ayudar en el camino judicial o en la impugnación formulada y con los alcances que la misma tiene, muchas veces obligando a derogar la norma cuestionada.

Así presentado el caso, de acuerdo a la Ordenanza Procesal, en los artículos $8^{\circ}$ y siguientes, la misma debe formularse por escrito en la mesa de entradas de la Comisión ubicada en Maipú 267, 9no piso, en tres copias y debe constituirse domicilio en Capital Federal. También se puede enviar por correo la presentación y deberá, además de aportarse la prueba documental, cumplir con los siguientes requisitos: 1) el nombre y domicilio del peticionante, la determinación del gravamen que se cuestione como opuesto al régimen de la ley 23.548 estableciendo el efecto a las normas respectivas de las que surjan los gravámenes que se consideran en 
oposición, la exposición de las razones de la demanda y el ofrecimiento de toda la prueba. Se debe acompañar copia autenticada de la norma que se impugna, en los artículos 10 y 11 de la Ordenanza Procesal.

Admitida formalmente la demanda, la Comisión le da traslado a la provincia o, en su caso la Nación, por el plazo de treinta días, para que la conteste con los mismos requisitos formales de la demanda. Luego se resuelve si procede o no la apertura a prueba, caso contrario se declarará la causa como de puro derecho, donde se podrá presentar un memorial. Si se abre a prueba, se presentará un alegato sobre el mérito de la misma, en el art. 17 de la Ordenanza Procesal. Luego se dará vista a la asesoría jurídica, y luego se dicta resolución en el término de sesenta días, no contando la decisión de la Comisión Federal con imposición de costas ni regulación de honorarios, en los arts. 19 y 20 de la Ordenanza Procesal.

Contra las resoluciones del Comité Ejecutivo, se puede presentar un recurso de revisión ante la Comisión Federal y contra la resolución de ésta última, recurso extraordinario ante la Corte Suprema de Justicia de la Nación, en el art 25 de la Ordenanza Procesal. Ese recurso no es procedente de acuerdo a unánime jurisprudencia del Alto Tribunal, por no provenir de un tribunal de justicia. En tal sentido, se ha interpretado que la apelación del artículo 14 de la ley 48 sólo procede contra sentencias judiciales, es decir, provenientes de los órganos permanentes del Poder Judicial y de las provincias, y la Comisión en cuestión no tiene el carácter de un tribunal superior de la causa, por lo que no procede el mismo, en la sentencia del 22 de septiembre de 1983. Al ser una instancia arbitral al que las partes se someten, una vez firme, y de acuerdo al artículo 12 de la ley 23.548: "Las decisiones de la Comisión serán obligatorias para la Nación y las provincias adheridas (...)".

Como ejemplos del tipo de decisiones que se toman, podemos citar casos en donde los denominados "derechos por publicidad y propaganda" fueron considerados, respecto de su aplicación por dicha actividad en el interior de locales comerciales, están en pugna con el régimen de coparticipación, en la Resolución 569/2011. En tal sentido, el artículo 13 dispone que:

La jurisdicción afectada por una decisión de la Comisión Federal de Impuestos deberá comunicar a dicho organismo, dentro de 
los noventa (90) días corridos contados a partir de la fecha de notificación de la decisión no recurrida o de los sesenta (60) días corridos contados a partir de la fecha de notificación de la decisión recaída en el período de revisión según los términos del artículo 12, en su caso, las medidas que haya adoptado para su cumplimiento.

Vencidos dichos plazos sin haberse procedido en consecuencia, la Comisión Federal de Impuestos dispondrá lo necesario para que el Banco de la Nación Argentina se abstenga de transferir a aquélla, los importes que le correspondan sobre lo producido del impuesto a distribuir análogo al tributo impugnado, hasta tanto se dé cumplimiento a la decisión del organismo. Es decir, que la decisión de la Comisión es obligatoria y la Provincia o Municipio tiene dos meses para acreditar que acató la decisión, en caso de no hacerlo la Comisión le ordenará al Banco de la Nación Argentina que se abstenga de transferir los importes que correspondan sobre el impuesto análogo al coparticipado.

Por su parte, se dispone que para los casos de Resoluciones que resuelvan casos en pugna con el régimen, quienes no hayan sido parte, pueden reclamar ante el Fisco respectivo. Así el artículo 14 de la ley dispone:

Los contribuyentes afectados por tributos que sean declarados en pugna con el régimen de la presente ley, podrán reclamar judicial o administrativamente ante los respectivos fiscos, en la forma que determine la legislación local pertinente, la devolución de lo abonado por tal concepto sin necesidad de recurrir previamente ante la Comisión Federal de Impuestos.

De tal manera, los contribuyentes invocando la sola decisión de la Comisión Federal se podrán presentar ante los Fiscos respectivos o la justicia a pedir la devolución de las sumas que hubieran abonado sin necesidad de acudir previamente a la Comisión Federal de Impuestos. Lo esperable es que el Fisco proceda a la devolución sin obligarlo a transitar un camino que culmine en la justicia.

\section{La reforma constitucional de 1994 y el régimen de coparticipación}

La reforma constitucional de 1994 constitucionalizó el régimen de coparticipación plasmándose de esta manera la forma de distribución que 
Distribución del poder tributario en Argentina el régimen de Coparticipación Federal de impuestos

ya había adoptado Argentina. Así plasmó en la parte pertinente del artículo 75 que:

Una ley convenio, sobre la base de acuerdos entre la Nación y las provincias, instituirá regímenes de coparticipación de estas contribuciones, garantizando la automaticidad en la remisión de los fondos.

La distribución entre la Nación, las provincias y la ciudad de Buenos Aires y entre éstas, se efectuará en relación directa a las competencias, servicios y funciones de cada una de ellas contemplando criterios objetivos de reparto; será equitativa, solidaria y dará prioridad al logro de un grado equivalente de desarrollo, calidad de vida e igualdad de oportunidades en todo el territorio nacional.

La ley convenio tendrá como Cámara de origen el Senado y deberá ser sancionada con la mayoría absoluta de la totalidad de los miembros de cada Cámara, no podrá ser modificada unilateralmente ni reglamentada y será aprobada por las provincias._No habrá transferencia de competencias, servicios o funciones sin la respectiva reasignación de recursos, aprobada por ley del Congreso cuando correspondiere y por la provincia interesada o la ciudad de Buenos Aires en su caso. Un organismo fiscal federal tendrá a su cargo el control y fiscalización de la ejecución de lo establecido en este inciso, según lo determina la ley, la que deberá asegurar la representación de todas las provincias y la ciudad de Buenos Aires en su composición._En resumen, la Constitución Nacional luego de la reforma de 1994 dispone que:

a. Se adoptó el sistema de coparticipación como manera de coordinar el ejercicio del poder tributario, pudiéndose establecerse varios regímenes de coordinación que son acuerdos entre la Nación y las Provincias.

b. La distribución que disponga la ley debe contemplar o tener relación directa con las competencias, servicios y funciones que brinde cada ente de gobierno.

c. La ley debe tener origen en el Senado en donde están representados todos los representantes de las Provincias y debe ser aprobada por las legislaturas provinciales sin poder modificarla unilateralmente ni reglamentarla 
d. No se pueden transferir competencias, servicios o funciones sin la reasignación de recursos pertinente

e. Un organismo fiscal federal tendrá a cargo el control y fiscalización de la ejecución de la ley y debe asegurar la representación de las provincias y de la Ciudad de Buenos Aires.

Esas son los lineamientos programáticos que impone la Constitución Nacional desde el año 1996 que el convencional sostuvo que debía dictarse un nuevo régimen, conforme se desarrolla en otro punto del presente. Esto hasta la fecha no ha ocurrido, dando lugar a lo que podría denominarse una clara inconstitucionalidad por omisión.

\section{Necesidad del dictado de una nueva ley de coparticipación}

El convencional constituyente de 1994 plasmó en la cláusula transitoria sexta que:

Un régimen de coparticipación conforme lo dispuesto en el inc. 2 del Artículo 75 y la reglamentación del organismo fiscal federal, serán establecidos antes de la finalización del año 1996; la distribución de competencias, servicios yfunciones vigentes a la sanción de esta reforma, no podrá modificarse sin la aprobación de la provincia interesada; tampoco podrá modificarse en desmedro de las provincias la distribución de recursos vigente a la sanción de esta reforma y en ambos casos hasta el dictado del mencionado régimen de coparticipación. La presente cláusula no afecta los reclamos administrativos o judiciales en trámite originados por diferencias por distribución de competencias, servicios, funciones o recursos entre la Nación y las provincias.

Desde el año 1996 es que debió sancionarse una nueva ley de coparticipación, objetivo incumplido lo que permite que se aplique la actual ley 23.548 a raíz que hasta que no tenga lugar un régimen sustitutivo ello no ocurrirá. Es por ello que resulta importante que se proceda a dictar una nueva ley de coparticipación para poder cumplir con el objetivo constitucional y no evitarse tal discusión, con la firma de pactos o acuerdos que no cumplen con el objeto respectivo. Es evidente, que la ley de dictarse ya que es una de las más importantes de nuestro régimen constitucional y 
legal. La falta de dictado de una nueva ley de coparticipación debilita el sistema actualmente vigente que tiene más de treinta años sin una reforma orgánica y uniforme que reconozca las particularidades de las provincias y el Estado Nacional en materia de competencia de servicios y funciones.

\section{La Codificación en materia tributaria en la República Argentina}

Se discute y brega mucho en doctrina por la codificación del derecho tributario, para contar con un cuerpo orgánico de normas, con parte general y especial que rija esta materia específica del derecho, que goza autonomía científica, funcional y pedagógica. Se sostiene que una de las dificultades que presenta la materia tributaria es su mutabilidad y cambios, dado por el hecho de la gran cantidad y variedad de normas que se dictan en el tema. Un Código ayudaría en esta cuestión de la dificultad de alcanzar o comprender los temas tributarios. Razones de certeza, seguridad jurídica y conocimiento de las normas son las que aconsejan que se establezca la codificación del tema en nuestro país. Existen materia "codificadas" que son reguladas por el Congreso Nacional de acuerdo al artículo 75 inciso 12) de nuestra Constitución Nacional y que rigen en todo el país, como el Código Civil y Comercial de la Nación y el Penal entre otras materias. Sin embargo, no existe un "Código Unificado Tributario" ni muchos menos, por ser nuestro país federal, un Código Tributario Local o Municipal.

Este punto, se tiene como finalidad poder enseñar a donde buscar, en qué legislación en los casos en los que se presenta un tema o conflicto tributario a nivel local. En otras palabras que cuerpo normativo se debe buscar para abordar esa temática y poder empezar a analizar el tema. En materia tributaria, para poder analizar el tema de la codificación y llegar a una conclusión, debemos separar entre el Estado Nacional, las provincias y los municipios, que como se dijo con distinto alcance y límites cuentan con poder tributario, y por ende, con la posibilidad de establecer sus tributos. El Estado Nacional en materia tributaria, como se vio cobra tributos sobre el comercio exterior, seguridad social e impuestos sobre renta, patrimonio y consumo en general. Desde ya es sabido que no existe un Código Tributario Nacional unificado, como el Penal o el Civil y Comercial de la Nación, en donde puedan buscarse esos temas. Una decisión política podría crear el mismo, lo que le daría mayor certeza y accesibilidad a los operadores jurídicos y a la ciudadanía en general que necesitan conocer las normas 
aplicables. ¿Pero, existe codificación a nivel del Estado Nacional en materia tributaria? Como se adelantó para ver el tema de la codificación a nivel nacional, es importante separar respecto a la aplicación de la tributación en cada caso, y sobre que distintos "rubros" o materias cobra tributos el Estado Nacional.

Así las cosas, en materia de comercio internacional sí existe codificación, ya que está vigente el Código Aduanero (Ley 22.415) que data del año 1981, que consta de una parte "general" en donde se regulan los sujetos, control, importación, exportación entre otros aspectos y una parte con los "regímenes especiales", en donde se destacan los regímenes especiales y los delitos aduaneros en particular. Por ello, podemos afirmar que existe codificación en materia aduanera y de comercio exterior, siendo el único Código como tal aplicable al Estado Nacional. No existe codificación estrictamente en las restantes materias tributarias que el Estado Nacional se encarga (caso de los impuestos y seguridad social). Lo que sí existe es una suerte de "Código" de la parte general que es la ley de procedimiento tributario $N^{\circ} 11.683$ (t.o. en 1998 y sus modificaciones), que regula lo que sería esa parte general de un Código, a saber, disposiciones generales, sujetos de los deberes impositivos, determinación y percepción de impuestos, del pago, intereses, ilícitos y sanciones, parte procesal, vías recursivas, Tribunal Fiscal de la Nación, modos de extinción, ejecución fiscal etc.

Pero luego existen leyes para cada uno de los impuestos en particular (ganancias, impuesto al valor agregado, a los bienes personales, etc). De tal forma, que cuando uno tiene un tema con respecto a un tributo nacional, que no sea sobre el comercio exterior, deberá ubicar la respectiva ley y decreto reglamentario, y en materia general para todo lo no regulado aplicar la ley de procedimiento tributario. Por su parte, tema que esté relacionado con la seguridad social deberá buscarse las leyes respectivas de la materia, no contando con un código unificado sobre la materia.

Donde sí existe codificación es en las veintitrés provincias y en la Ciudad Autónoma de Buenos Aires, así como también a nivel municipal o comunal. Ello es así por cuanto cada una de las provincias y la Ciudad Autónoma de Buenos Aires tienen su Código Fiscal, con una parte general en donde se regulan aspectos formales y materiales de la relación tributaria, vías recursivas, procedimiento de ejecución fiscal, etc y además una parte especial en donde encontraremos los tributos en particular que cobra la 
respectiva provincia, que de acuerdo a la ley de coparticipación a saber ingresos brutos, sellos, automotor y embarcaciones deportivas, inmobiliario y transmisión gratuita de bienes (vigente únicamente en la Provincia de Buenos Aires), así como también las tasas retributivas de servicios que cobran las provincias. Por otra parte, anualmente se dictan las leyes tarifarias o impositivas en donde se fijan los montos a cobrar y las alícuotas pertinentes para cada tributo y actividad, esencialmente para el impuesto sobre los ingresos brutos.

Por su parte, en materia municipal también existe codificación ya que cada municipalidad cuenta con su Ordenanza Fiscal y su Ordenanza Tarifaria, encontrando en el primer caso una parte general en donde se regulan los deberes formales, materiales, sanciones, procedimiento de determinación de oficio, vías recursivas, etc y en la segunda los tributos en particular que cobran los municipios, esencialmente de acuerdo a nuestro régimen constitucional, las tasas retributivas de servicios. A su turno, la Ordenanza Tarifaria dispondrá las alícuotas y montos que cobran los municipios. En concreto, en el tema concreto de la Codificación podemos afirmar que:

1. Solamente existe Codificación a nivel nacional con el Código Aduanero, y las restantes materias -impositiva y recursos de la seguridad social -se rigen por leyes específicas y la ley de procedimiento tributario en materia procesal con aspectos de fondo que la misma regula.

2. Existe Codificación a nivel provincial, la Ciudad Autónoma de Buenos Aires y los municipios.

\section{Publicación de las Ordenanzas Municipales}

Relacionado con el tema de la publicación de las normas y actos de gobierno, debe decirse que nivel nacional no hay problema ya que las mismas se publican en el Boletín Oficial desde hace décadas. Pero ello no fue tan claro a nivel municipal, para lo cual efectuaré una breve descripción histórica, para poder concluir el estado actual del tema con referencia a la Provincia de Buenos Aires. La publicación de las ordenanzas municipales, su obligatoriedad o no y por qué medios debe disponerse la misma, es una cuestión que ha generado bastante litigiosidad y controversias entre 
los fiscos municipales y los contribuyentes. La difusión y conocimiento de ordenanzas municipales (en lo que al presente interesa fiscales e impositivas) que establecen tributos es fundamental en un estado de derecho y razones de certeza y seguridad jurídica así lo aconsejan.

Se ha dicho que "las normas jurídicas, para poder ser cumplidas por sus destinatarios, deben ser conocidas y, para ello es menester, en una sociedad de masas, como la contemporánea que hayan sido publicadas" (Casas, 2005). Cabe considerar que conforme lo dispone el artículo 19 de la Constitución Nacional "ningún habitante de la Nación será obligado a hacer lo que la ley no manda, ni privado de lo que ella no prohibe" y que en materia tributaria rige el principio de legalidad, receptado en el artículo 17 de la Constitución Nacional. Algo tan básico y neurálgico es el hecho de que las normas dictadas sean conocidas por sus destinatarios para que puedan ser cumplidas.

En la República Argentina existen más de dos mil doscientos cincuenta (2250) municipios, y solamente en la Provincia de Buenos Aires hay ciento treinta y cinco (135), en los que cada uno de ellos tiene diferentes características, costumbres e incluso acceso a herramientas tecnológicas e informáticas. La difusión de su normativa es algo importante y que da certeza en la relación Fisco y contribuyente, que tiende a evitar conflictos y controversias. El tema, ha generado particular controversia en el tributo que cobran los municipios denominado "derechos por publicidad y propaganda", que en muchos casos el reclamo se endereza directamente contra el "beneficiario" o "titular" de la publicidad, que es en la mayoría de los casos el titular de la marca o el que tiene el derecho a explotarla, que carece de asiento o presencia en el municipio que le cobra. En ese caso, se ha planteado como dichos sujetos toman conocimiento que son sujetos pasivos del tributo, lo que ocurre como veremos muchas veces de acuerdo a la reseña que se realizará con el inicio de un juicio de apremio. En otras palabras, como se toma conocimiento de la normativa en cuestión, para poder cumplir con los deberes formales y materiales a su cargo, de ahí la jurisprudencia que se fue gestando en la materia. Es fundamental que se conozca las normas por parte de los destinatarios legales tributarios para que éstos puedan cumplir con la misma, o, en su caso impugnarla por las razones que consideren pertinentes. 
En la presente colaboración se analizará el tema, con especial referencia a la evolución de la normativa en la Provincia de Buenos Aires, con referencia a la jurisprudencia y haciendo especial referencia a reciente jurisprudencia de nuestro más Alto Tribunal. Finalmente se formulan algunas conclusiones que tienen como finalidad contribuir a este tema y a evitar dar un aporte a tan controvertida cuestión. Cabe considerar que, en primer lugar, la Constitución de la Provincia de Buenos Aires, dispone en el artículo 191 que la Legislatura deslindará las atribuciones y responsabilidades de cada departamento, confiriéndoseles las facultades necesarias para que puedan atender eficazmente todos los intereses y servicios locales, con sujeción a las reglas que enumera. Por su parte, el artículo 193 de la Constitución establece que "Las atribuciones expresadas tienen las siguientes limitaciones: 1) Dar a publicidad por la prensa a todos sus actos, reseñándolos en una memoria anual, en la que se hará constar detalladamente la percepción e inversión de sus rentas" (lo destacado me corresponde).

En el tema se debe analizar la Ley Orgánica de Municipalidades (decreto ley 6769/58) y la Ordenanza General 267/80 que se encuentran vigentes, con sus respectivas modificatorias.

La ley Orgánica de Municipalidades disponía -ya que fue modificada como se analizará-en el artículo 108 dentro de las atribuciones del Intendente la de promulgar y publicar las disposiciones del Consejo o vetarlas dentro de los diez días hábiles de su notificación, caso contrario, quedarán convertidas en ordenanzas. En forma coincidente la Ordenanza General 267/80 (regulatoria del procedimiento administrativo y de producción de los actos administrativos) dispone en el artículo 125 que "los reglamentos administrativos producirán efectos jurídicos a partir del día siguiente al de su publicación por medio que determine el Departamento Ejecutivo" (lo destacado me corresponde). Esas normas atribuían al Departamento Ejecutivo la facultad de promulgar y publicar las ordenanzas municipales, y determinar razonablemente el medio de publicidad a ser utilizado. Se entendía que debían darle adecuada difusión a tales actos legislativos, por el medio que eligiesen en el Departamento Ejecutivo del respectivo municipio. No existía de acuerdo a esas normas, en la Provincia de Buenos Aires, la obligatoriedad de organizar un boletín informativo municipal ni la obligación de publicas las ordenanzas en un Boletín Oficial, sino que 
establece la forma de difusión estaba en cabeza del Intendente Municipal como ya se adelantó.

En ese sentido, esa facultad delegada al Intendente Municipal fue reconocida por la Suprema Corte de Justicia de Buenos Aires hace muchos años al sostener que "La Ley Orgánica de Municipalidades atribuye al Departamento Ejecutivo la promulgación y publicación de ordenanzas $y$, consecuentemente, cabe reconocerle atribuciones para determinar razonablemente el medio de publicidad a utilizar" (Suprema Corte de Justicia de la Provincia de Buenos Aires, 1989). De tal manera, se tuvo por válida la manera en que el Intendente daba difusión a sus normas al sostener: "(...) la difusión a través de los medios masivos de comunicación y la comunicación a los vecinos de lo dispuesto mediante la exhibición de la copia de la mencionada Ordenanza en el hall central del Municipio" (Suprema Corte de Justicia de la Provincia de Buenos Aires, 1998). Como se ve se aceptó la difusión en un medio masivo de comunicación (diario, televisión, etc) y con el hecho de poner copia de la Ordenanza en el Municipio. Se puede ver que ello es una verdadera ficción a que un acto de gobierno pueda ser difundido debidamente.

Como veremos, esas facultades y su aplicación por parte del Intendente Municipal han dado una serie de fallos que son relevantes en el tema, ya que los medios utilizados en muchos casos no cumplieron con la adecuada difusión exigida. Un caso emblemático respecto a la publicación de las Ordenanzas Municipales, si bien de un municipio de la Provincia de Misiones, no de la de Buenos Aires, es el caso del rechazo de una ejecución fiscal por falta de publicación de la normativa que había creado el tributo. En tal sentido, en el año 2004 nuestro más Alto Tribunal, al adherirse al dictamen del Procurador sostuvo en la conocida causa "Municipalidad de Santiago de Liniers c/ Irizar, José Manuel s/ apremio" sentencia del 19 de octubre de 2004:

(...) la demandada opuso, desde su primera presentación en juicio, la defensa basada en la inexistencia de deuda, pues esgrimió que la ordenanza que establece el tributo no ha sido publicada en el Boletín Oficial provincial ... el municipio sólo realizó una negativa genérica sobre la cuestión, sin acompañar copia de la publicación cuya existencia afirma, no especifica el día o el número de boletín en que tal acto ha ocurrido (...) la 
solución definitiva del caso sólo requiere la simple constatación de la publicación oficial de la mencionada ordenanza, acto requerido para la satisfactoria divulgación y certeza sobre la autenticidad del texto de aquellas decisiones de contenido normativo general (...) la sencilla verificación de tal extremo no afecta el carácter ejecutivo de la acción promovida.

En particular referencia a la jurisprudencia en materia provincial, se fueron dando fallos que analizaron el alcance de la publicación por la prensa y difusión de las ordenanzas que disponen tributos. Se presentaron varios casos en donde el Intendente había utilizado diversos medios de publicación con diversos criterios pero que, a criterio de la jurisprudencia no cumplían con una finalidad de una adecuada difusión. Se dijo que:

(...) resulta notoriamente insuficiente la publicación en una "cartelera municipal", que no cumple con la exigencia de publicación por la prensa del art. 193 de la Constitución provincial, ni con los principios emanados de la Constitución Nacional, entre los cuales cabe incluir el requisito de la publicación de las leyes y de toda norma de alcance general para su plena vigencia y aplicación a sus destinatarios (Juzgado de Paz Letrado de Chivilcoy, 2010).

Como se puede ver la jurisprudencia evolucionó y se dejó de lado el criterio de la Suprema Corte provincial. También se dijo que:

(...) en el caso de la provincia de Buenos Aires, los arts. 108 de la LOM y 125 de la ordenanza general 267 no prevén expresamente a través de que medio debe llevarse a cabo la publicidad de las ordenanzas municipales (...) al afirmar que el Poder Ejecutivo tiene atribuciones para determinar razonablemente el medio a utilizar para la publicidad de las ordenanzas, no puede servir de fundamento para eximirlo de darle la debida difusión

Y se hace lugar a la inhabilidad de título por "ausencia de debida divulgación de la ordenanza fiscal municipal en la que se establece el tributo" (CCiv y Com de Azul, 2009).

La Corte Suprema de Justicia de la Nación llegó a pronunciarse en esta clase de temas al pronunciarse en un precedente que luego fue citado en 
muchos otros: "Recurso de hecho deducido por la demandada en la causa Municipalidad de Mercedes c/ Arcor SAIC s/ apremio" (Sentencia del 7 de agosto de 2012. Fallos 335:1459). Allí se compartieron los fundamentos del dictamen de la Procuradora Fiscal en donde se dijo:

En el sub lite Arcor SAIC opuso desde su primera presentación en juicio, la defensa basada en la inexistencia de deuda, pues esgrimió que la ordenanza que establece el tributo no ha sido publicada ... el municipio sólo realizó una negativa genérica sobre la cuestión, sin acompañar copia de la publicación ni individualizar sus datos, oponiéndose expresamente a la producción de la prueba ofrecida por la actora (...) no puede dejar de señalarse que contrariamente a lo sostenido por el juez de grado, la solución definitiva del caso sólo requiere la simple constatación de la publicación de la mencionada ordenanza, acto requerido para la satisfactoria divulgación y certeza sobre la autenticidad del texto de aquellas decisiones de contenido normativa general (...) y qué, en la especie, la sencilla verificación de tal extremo no parece afectar el carácter ejecutivo de la acción promovida.

En fecha aún más reciente se dispuso en un caso en el cual la Suprema Corte Provincial había confirmado la sentencia de Cámara que en el marco de un juicio de apremio había rechazado la inhabilidad de título, la Corte sostuvo que "los tribunales se encuentran obligados a tratar y resolver adecuadamente las defensas fundadas en la inexistencia de deuda, siempre que ello no presuponga el examen de otras cuestiones cuya acreditación exceda el ámbito limitado de dichos procesos", y que

La solución definitiva del caso solo requiere la simple constatación de la publicación oficial de la mencionada ordenanza, acto requerido para la satisfactoria divulgación y certeza sobre la autenticidad del texto de aquellas decisiones de contenido normativo general, sin que ello afecte el carácter ejecutivo de la acción promovida.

Y concluyó que:

(...) el tribunal debió evaluar si la publicación en la página oficial del municipio ... reúne los requisitos necesarios para 
garantizar que se trata de una publicación oficial que otorgue una satisfactoria divulgación y certeza respecto de la autenticidad del texto, su publicación y permanencia en el tiempo durante los períodos fiscales que se le reclaman.

Como se puede ver, se exige que en los casos, incluso de juicios de apremio, en donde se desconoce la deuda por falta de publicación de la ordenanza, se identifique la misma y como ha sido difundida y publicada, caso contrario su rechazo palmario de esa defensa es una sentencia arbitraria. Como ocurre en muchos casos la jurisprudencia obligó al cambio de la legislación que resultaba aplicable en la materia. En tal sentido, se modificó la Ley Orgánica de Municipalidades de la Provincia de Buenos Aires (Decreto-Ley 6769/58) en el mes de diciembre de 2012 con el dictado de la ley 14.491. Es importante para conocer el alcance de la reforma referirse a los fundamentos de la ley, para lo cual se los transcribe íntegramente: El presente proyecto tiene por finalidad modificar el artículo 108 de la del Dec-Ley 6769/58 "Ley Orgánica de las Municipalidades", a los efectos de que dicho cuerpo legal recepte de manera amplia y plenamente el principio republicano, en materia de publicidad de los actos de gobierno.

Se consagra de esta manera la garantía en materia de transparencia y acceso a la información con que cuentan los ciudadanos de la provincia de Buenos Aires, en concordancia con el Artículo 12 inciso 4), de la Carta Magna provincial estableciendo que todas las personas en la Provincia gozan del derecho a la información y la comunicación; con la Ley Nro. 12.475 reconoce a toda persona física o jurídica que tenga un interés legítimo, el derecho de acceso a documentos administrativos cuya divulgación no se encuentre prohibida expresamente. Actualmente la Ley Orgánica Municipal atribuye al Departamento Ejecutivo Municipal la promulgación y publicación de Ordenanzas. El tema de la vigencia de las Disposiciones normativas (fundamentalmente las de carácter general, como las ordenanzas) es importante a la hora de juzgar la eficacia del sistema republicano. La Provincia de Buenos Aires no exige en su legislación, como bien lo hace su par cordobesa, la organización de un Boletín informativo Municipal.

Así se contempla la obligación de los Municipios de confeccionar un boletín, publicarlo en forma mensual, ponerlo a conocimiento de la población en forma gratuita y en lugares públicos... (Ley 
Orgánica de las Municipalidades de la Provincia de Buenos Aires, Iván Tenaglia, Librería Editora Platense, Edición 2000, comentario al artículo 24, Página 61).

Por otra parte, si bien algunos municipios -no todos- de la Provincia de Buenos Aires en la práctica cuentan con Boletines Oficiales, el acceso a los mismos por parte de los ciudadanos no es un trámite sencillo, más aún cuando se trata de buscar normas o temas legales con referencias escasas, o acceder a ellas desde lugares alejados o desde otras jurisdicciones. Por lo expuesto, la incorporación de las nuevas tecnologías de la comunicación y de la información (Tics) y en particular a través de las páginas Web oficiales los Municipios los Departamentos Ejecutivos en el marco de sus exclusivas competencias pueden facilitar un rápido y ágil acceso a la información en materia de normas legales promulgadas. También cabe señalar que existe normativa provincial que requiere de la adhesión voluntaria de los municipios, mediante ordenanza para su entrada en vigencia en la jurisdicción local; no existiendo en la actualidad un sistema de registro que verifique y ordene dichas adhesiones.

En consecuencia, la ley promueve la creación de este Registro Oficial atento la necesidad de contar con un instrumento que permita coordinar con los Municipios la aplicación e interpretación de la normativa provincial adherida por las Municipalidades en lo referente a una más eficiente administración local. Como se sostuvo anteriormente, en este caso la respuesta de la jurisprudencia al tema, fue la que forzó el cambio legislativo para que se respete el principio basal de la seguridad jurídica y de certeza en un tema tan importante como es el de la publicación de las normas y difusión de los actos de gobierno. De ahora en más los municipios deben cumplir con la publicación de las ordenanzas por medio de un Boletín Oficial Municipal, y es de suma importancia que también tengan difusión en la página web del Municipio. No se puede exigir el cumplimiento de una norma si la misma no es obligatoria por no a ver sido conocida por sus destinatarios por ausencia de difusión.

En tal sentido, existe el Sistema de Boletines Oficiales Municipales (SIBOM) que es una plataforma web a través de la cual los municipios que integran la Provincia de Buenos Aires, podrán elaborar sus Boletines Oficiales, de conformidad con las disposiciones de la Ley 14.491. En este punto, es importante considerar las características particulares de cada 
municipio pero el uso de herramientas informáticas y de publicación en las páginas web es sin dudas algo que ayudará a la difusión de sus normas y porque no a la recaudación. También deberían reducirse los planteos defensivos de los contribuyentes a partir del 2013 de la ausencia de publicación de las normas ya que será un hecho de fácil prueba y refutación para el municipio.

\section{Consenso fiscal y obligaciones de las provincias}

En los últimos años, el Estado Nacional ha optado por suscribir consensos fiscales o pactos en lugar de cumplir con la obligación constitucional de dictar un nuevo régimen de coparticipación federal de impuestos. Cabe recordar que todos estos pactos forman parte como dice la Corte del derecho público provincial, al igual que el régimen de coparticipación, con lo cual su vulneración es parte del derecho local y no se abre la competencia federal. El último de los Consensos Fiscales está dado por el firmado el 16 de noviembre de 2017 en donde se destaca dentro de los compromisos comunes el de:

(...) consensuar una nueva ley de coparticipación federal de impuestos en el marco de la Comisión Federal de Impuestos que, cumpliendo con el mandato constitucional, esté basada en las competencias, servicios y funciones de cada jurisdicción, contemple criterios objetivos de reparto y logre las metas de solidaridad, equidad y de alcanzar un grado equivalente de desarrollo, calidad de vida e igualdad de oportunidades.

Existen un conjunto de obligaciones por parte de las provincias y la Ciudad de Buenos Aires asumidas en este Compromiso a saber:

\section{Impuesto sobre los Ingresos Brutos}

a. Eliminar inmediatamente tratamientos diferenciales basados en el lugar de radicación o la ubicación del establecimiento del contribuyente o el lugar de producción del bien.

b. Desgravar inmediatamente los ingresos provenientes de las actividades de exportación de bienes, excepto las vinculadas con actividades mineras o hidrocarburíferas y sus servicios complementarios, 
c. Desgravar los ingresos provenientes de prestaciones de servicios cuya utilización o explotación efectiva se lleve a cabo en el exterior del país,

d. Establecer exenciones y aplicar alícuotas del impuesto no superiores a las que para cada actividad y período se detallan en el Anexo I de este Consenso,

e. Adecuar el funcionamiento de los regímenes de retención, percepción y recaudación del gravamen de manera tal de respetar el límite territorial de la potestad tributaria de las jurisdicciones, según lo previsto en el Convenio Multilateral, y evitar la generación de saldos a favor inadecuados o permanentes, que tornen más gravosa la actuación interjurisdiccional del contribuyente, respecto de su actuación pura en el ámbito local,

f. Establecer un mecanismo de devolución automática al contribuyente del saldo a favor generado por retenciones y percepciones, acumulado durante un plazo razonable, que en ningún caso podrá exceder los 6 (seis) meses desde la presentación de la solicitud efectuada por el contribuyente, siempre que se encuentren cumplidas las condiciones y el procedimiento establecido por las jurisdicciones locales para esa devolución.

\section{Impuesto Inmobiliario}

a. Adoptar para el cálculo y determinación de las valuaciones fiscales de los inmuebles los procedimientos y metodologías de valuación uniformes establecidos por el organismo federal. Para ello, las provincias y la CABA asegurarán a ese organismo federal acceso a los registros catastrales y demás registros locales. En los casos en que el tributo fuera de competencia municipal, los gobiernos provinciales impulsarán acuerdos para que los municipios apliquen igual criterio para la determinación de la base imponible,

b. Fijar alícuota del Impuesto Inmobiliario en un rango entre 0,5\% y $2 \%$ del valor fiscal establecido conforme lo previsto en el punto anterior, 


\section{Impuesto a los Sellos}

a. Eliminar inmediatamente tratamientos diferenciales basados en el domicilio de las partes, en el lugar del cumplimiento de las obligaciones o en el funcionario interviniente,

b. No incrementar las alícuotas del Impuesto a los Sellos correspondientes a la transferencia de inmuebles y automotores y a actividades hidrocarburíferas y sus servicios complementarios,

c. Establecer para el resto de los actos y contratos, una alícuota máxima de Impuesto a los Sellos del 0,75\% a partir del $1^{\circ}$ de enero de 2019,0,5\% a partir del $1^{\circ}$ de enero de 2020,0,25\% a partir del $1^{\circ}$ de enero de 20121 y eliminarlo a partir del $1^{\circ}$ de enero de 2022.

\section{Municipios}

a. Establecer un régimen legal de coparticipación de recursos provinciales con los municipios,

b. Establecer un régimen legal de responsabilidad fiscal, similar al nacional, para sus municipios, impulsar que éstos adhieran y controlar su cumplimiento,

c. Promover la adecuación de las tasas municipales aplicables en las respectiva jurisdicciones de manera tal que se correspondan con la concreta, efectiva e individualizada prestación de un servicio y sus importes guarden una razonable proporcionalidad con el costo de este último, de acuerdo con lo previsto en la Constitución Nacional,

d. Crear una base pública, por provincia, en la que consten las tasas aplicables en cada municipalidad (hechos imponibles, bases imponibles, sujetos alcanzados, alícuotas y otros datos relevantes) y su normativa,

e. Impulsar un sistema único de liquidación y pago de tasas municipales aplicable a cada provincia y la CABA 
Por su parte el Estado Nacional, en lo que al presente interesa dispuso:

Consensuar una nueva ley de coparticipación de impuestos en el marco de la Comisión Federal de Impuestos que, cumpliendo con el mandato constitucional, esté basado en las competencias, servicios y funciones de cada jurisdicción, contemple criterios objetivos de reparto y logre las metas de solidaridad, equidad y de alcanzar un grado equivalente de desarrollo, calidad de vida e igualdad de oportunidades.

Con respecto al cumplimiento de las obligaciones asumidas, en referencia al impuesto sobre los ingresos brutos para el 2018 se concluyó que

Puede apreciarse que de las 10 provincias que subieron la alícuota máxima sobre el sector comercio 6 lo hicieron llevándola al límite máximo permitido por la ley para el año 2019. En este grupo se encuentran Chubut, Salta, Río Negro, Tierra del Fuego, Entre Ríos y Santa Fe, En el grupo que subió alícuotas sin llega al máximo de 2019 se encuentran La Rioja, Jujuy y La Pampa. Y por último se destaca Neuquén, que subió la alícuota máxima al $6,5 \%, 1,5$ puntos porcentuales por encima del máximo que para 2019, que es del 5\% (Cámara Argentina de Comercio y Servicios, 2018). La historia demuestra que esta clase de pactos o acuerdos no resuelven el tema de fondo, que es la imperiosa necesidad de una nueva ley de coparticipación, para que realmente se cumpla con el objetivo del convencional y haya un régimen que exprese realmente un real federalismo fiscal. Esta clase de acuerdos o pactos se parecen más a imposiciones del Estado Nacional a las Provincias, siempre que se abstengan de cobrar tributos, a cambio de recibir recursos.

\section{Conclusiones}

a. La Constitución Nacional distribuye el poder tributario tomando como criterio de distinción los impuestos directos e indirectos, en donde la doble o múltiple imposición por parte de diferentes niveles de gobierno es perfectamente válida 
b. Para atenuar la doble imposición, existen regímenes de coordinación, siendo el actualmente vigente el régimen de coparticipación federal de impuestos, ley 23.548 vigente desde el año 1987, por abarcar la mayor cantidad de impuestos que se cobran sobre la renta, el patrimonio y el consumo.

c. La principal obligación de la ley 23.548 es que el Estado Nacional recauda y coparticipa, y las provincias por sí y por sus municipios no pueden establecer tributos análogos a los que reciben coparticipación,

d. Las provincias se reservaron el cobro de sus impuestos clásicos, como inmobiliario, patente, sellos e ingresos brutos.

e. En la reforma de la Constitución de 1994 se estableció que debía establecerse un nuevo régimen de coparticipación para el año 1996 cosa que a la fecha no se ha hecho, debilitándose el federalismo fiscal que pregona nuestra Constitución.

f. En lugar de reformar el régimen se han establecidos Pactos o Acuerdos fiscales entre el Estado Nacional y las Provincias que debilitan el federalismo, en lugar de sancionar una verdadera ley en la materia, ya que el Estado Nacional a cambio de otorgar recursos que les corresponden a las provincias les impone una serie de exigencias.

g. Existe Codificación en materia tributaria a nivel provincial y municipal, siendo muy importante la obligatoriedad de la publicación y difusión de las ordenanzas municipales para que sea de conocimiento de toda la población.

h. No existe Codificación a nivel del Estado Nacional, salvo en materia aduanera, lo que hace complejo el sistema actual.

\section{Referencias}

Casas, José O. (2015) Sentencia descalificada por no haber acreditado la publicación de ordenanza impositiva, Periódico Económico Tributario, La Ley.

CCiv y Com de Azul, Sala I, 11 de junio de 2009 Municipalidad de Benito Juarez c/ Gillete Argentina S.A. s/ apremio.

Código Aduanero. Ley 22.415 del año 1981 
Comisión Federal de Impuestos. Ordenanza Procesal. Recuperado de www. cfi.gov.ar

Constitución de la Nación Argentina del 1 de mayo de 1853

Corte Suprema de Justicia de la Nación, 28 de septiembre de 1927. Sociedad Anónima Mataldi Simón Limitada c/ Provincia de Buenos Aires.

Corte Suprema de Justicia de la Nación Sentencia del 7 de agosto de 2012. Fallos 335:1459

Corte Suprema de Justicia de la Nación, sentencia del 23 de agosto de 2018 Municipalidad de la Ciudad de La Banda c/ Gobierno de la Provincia de Santiago del Estero s/ conflicto entre poderes públicos.

Corte Suprema de Justicia de la Nación, sentencia del 27 de septiembre de 2018 Municipalidad de Junín c/ Cadbury Stani Adams Argentina SAIC s/ apremio, y en forma coincidente en la misma fecha Municipalidad de Berazategui c/ Molinos Río de la Plata.

Corte Suprema de Justicia de la Nación, (Sin fecha) Fallos 322:1781

Corte Suprema de Justicia de la Nación, (Sin fecha) Fallos: 324: 4226

Corte Suprema de Justicia Nacional, (Sin fecha) Fallos 338: 1389

Corte Suprema de Justicia Nacional, (Sin fecha) Fallos 332:1007

Corte Suprema de Justicia Nacional, (Sin fecha) Fallos: 322:1781

Corte Suprema de Justicia Nacional, sentencia del 19 de octubre de 2004 Municipalidad de Santiago de Liniers c/ Irizar, José Manuel s/ apremio.

Casas, J. O. Sentencia descalificada por no haber acreditado la publicación de ordenanza impositiva, Periódico Económico Tributario, La Ley, 10 de febrero de 2005.

García Vizcaíno, (2017) C. Manual de Derecho Tributario, Abeledo Perrot. Informe Cámara Argentina de Comercio y Servicios, (2018) IARAF, Bajo el marco del Consenso Fiscal, hasta ahora 10 provincias ya subieron la alícuota máxima del impuesto a los ingresos brutos sobre el Sector Comercio.

Juzgado de Paz Letrado de Chivilcoy, 2 de noviembre de 2010. Municipalidad de Chivilcoy c/ Kraft Suchard Argentina s/ apremio.

Senado y Cámara de Diputados de la Nación Argentina (1998). Artículo 12 de la Ley 23.548. 
Senado y Cámara de Diputados de la Nación Argentina (1990). Artículo 4 de la Ordenanza Procesal

Senado y Cámara de Diputados de la Nación Argentina (1992). Artículo 8 y subsiguientes de la Ordenanza Procesal

Senado y Cámara de Diputados de la Nación Argentina (1994). Artículo 10 y 11 de la Ordenanza Procesal.

Senado y Cámara de Diputados de la Nación Argentina (1998). Artículo 17 de la Ordenanza Procesal.

Senado y Cámara de Diputados de la Nación Argentina (1998). Artículo 19 y 20 de la Ordenanza Procesal.

Senado y Cámara de Diputados de la Nación Argentina (1998) Artículo 25 de la Ordenanza Procesal

Senado y Cámara de Diputados de la Nación Argentina (1988). Ley 23.548 del 22 de enero de 1988

Senado y Cámara de Diputados de la Nación Argentina (2012). Ley 14.491 del 20 de diciembre de 2012. Recuperado de https://sibom.slyt.gba. gov.ar/cities/32

Sentencia del 24 de noviembre de 2015. Santa Fe, Provincia de c/ Estado Nacional s/ acción declarativa.

Suprema Corte de Justicia de la Provincia de Buenos Aires, 14 de noviembre de 1989, Santos, Eladio c/ Municipalidad de Bahía Blanca.

Suprema Corte de Justicia de la Provincia de Buenos Aires, 25 de Agosto de 1998, Gallardo, Alicia Angela c/ Municipalidad de Colón. 